\title{
A informação como potencializadora da autonomia e da integração social ${ }^{1}$
}

\author{
Information as a promoter of autonomy \\ and social integration
}

Maria Giovanna Guedes FARIAS²

\section{Resumo}

Os pressupostos teórico-metodológicos da Ciência da Informação podem fornecer subsídios para se investigar de que forma o uso estratégico da informação mediada pode contribuir para a diminuição da desigualdade por meio da experimentação dos princípios do protagonismo social. Essa reflexão indicou a trajetória seguida durante a pesquisa de doutorado sanduíche apresentada nesta comunicação, tendo como foco a construção de um possível modelo de integração social desenvolvido a partir da experiência vivenciada em uma comunidade italiana denominada Rione Sanità. As ações empreendidas em Sanità, as quais são retratadas no modelo, têm em seu arcabouço conceitual o objetivo de possibilitar aos moradores dessa localidade formas concretas, reais e legítimas de apropriação da informação, de autonomia, de empoderamento cultural e social. Escolheu-se a abordagem metodológica de cunho qualitativo para conduzir o trabalho no campo de pesquisa. Os dados foram coletados por meio de entrevistas e da observação participante e analisados pela técnica de análise de conteúdo de Bardin com o estabelecimento de categorias. Concluiu-se que os laços sociais e a identidade de grupos precisam ser repensados no sentido de considerar que somente a partir do respeito pelo diferente pode-se compreender o sujeito como único, o qual, no entanto, precisa do outro, de tudo que o rodeia e da união para sair do estado de degradação. A única dimensão possível é a experimentação contínua. Essa opção, no entanto, requer uma leitura permanente das condições do contexto, um acompanhamento constante de processos, uma presença assídua nos pontos de fragilidade, empreendendo ações de informação para e com os sujeitos pesquisados.

Palavras-chave: Empoderamento. Integração social - modelo. Mediação da informação. Protagonismo social.

\begin{abstract}
The theoretical and methodological assumptions of Information Science can contribute to the investigation of how the strategic use of mediated information can help reduce inequality through the application of the principles of social protagonism. This reflection guided a PhD sandwich research that resulted in the present article and focused on the development of a possible social integration model based on the experience gained in an Italian community called Rione Sanità. The actions undertaken in this community, described in the model proposed, were aimed at providing Sanità's residents with concrete, true, and legitimate appropriation of information, achievement of autonomy, and cultural and social empowerment. The qualitative research approach was used in the field research. Data were collected through interviews and participant observation, and were analyzed using content analysis as proposed by Bardin, establishing categories. It was concluded that social ties and group identity need to be rethought considering that only by respecting the differences, one can understand the subject as unique, but also as someone who needs others and everything surrounding him/her and union in order to fight against degradation. The only possible dimension is continuous experimentation; however, this requires constant monitoring of the existing conditions and processes focusing on the weaknesses, promoting information actions for and within the individuals studied.
\end{abstract}

Keywords: Empowerment. Social integration model. Mediation of information. Social protagonism.

\footnotetext{
1 Artigo elaborado a partir da tese de M.G.G. FARIAS, intitulada"Análise da produção, implementação eavaliação de um modelo de mediação da informação no contexto de uma comunidade urbana". Universidade Federal da Bahia, 2014.

2 Universidade Federal do Ceará, Centro de Humanidades, Departamento de Ciências da Informação. Av. daUniversidade, 2762, Benfica, 60020-181, Fortaleza, CE, Brasil.E-mail:<mgiovannaguedes@gmail.com>.
}

Recebido em 30/3/2015, reapresentado em 25/1/2016 e aceito para publicação em 25/2/2016. 


\section{Introdução}

A informação mediada exerce uma função primordial na promoção do diálogo com sujeitos que vivem, por exemplo, à margem da sociedade. Provoca nestes o interesse pela apropriação/empoderamento da informação, propiciando o surgimento da consciência do valor que esta terá sobre suas vidas. Não se pode, entretanto, pensar na perspectiva de que esses moradores, num primeiro momento, serão mediadores autônomos. É preciso que ações de integração social sejam aplicadas por meio de uma construção coletiva inspirada em teorias, como a da libertação de Paulo Freire, bem como ouvir e sentir o que os habitantes anseiam, visualizando o campo de pesquisa como um lugar repleto de protagonistas que exprimem seus desejos de modo diverso.

Essa reflexão guiou a pesquisa de campo desenvolvida no contexto de um estágio doutoral em Ciência da Informação, o qual ocorreu em um bairro do centro histórico da cidade de Nápoles, Itália, denominado Rion Sanità. Este é apresentado como um quartiere sensibile ${ }^{3}$ pelas características que o constituem, o que no Brasil pode ser considerado como uma comunidade. Essa escolha deu-se em razão da possibilidade de intercâmbio de conhecimentos durante vivência in loco nos trabalhos de integração social promovidos nesse quartiere. Essa experiência foi válida tanto do ponto de vista teórico (contato com autores italianos, alguns apresentados nesta comunicação) quanto metodológico (produção do modelo), subsidiando e aprimorando as ações que foram implantadas, posteriormente, em uma comunidade na cidade de João Pessoa (PB), campo de pesquisa brasileiro.

Enquanto no passado a experiência urbana fora considerada, conforme Cappelletti e Martinelli (2009, p.23), "[...] um habitat fértil para o nascimento de relações de pertencimento mútuo e solidariedade, hoje é precisamente no cenário urbano que a nova pobreza relacional se concentra e se radicaliza". Essa pobreza relacional, que causa desconforto, sofrimento individual, solidão e baixa autoestima nos indivíduos que vivem nessas áreas urbanas, acentua-se ainda mais graças à falta de políticas sociais adequadas. Neste sentido, os quartieri sensibili são configurados como espaços sociais onde vivem indivíduos socialmente marginalizados, desprovidos de toda esperança de realização humana e profissional, formando as "periferias humanas", expressão usada por Cappelletti e Martinelli (2009).

A ideia de cidade como um espaço de diferenças e desigualdades também é compartilhada por Magatti (2007). A autora a define como o objeto de análise provavelmente mais útil para se compreender as transformações sociais que ocorreram na contemporaneidade. Isso porque é nas cidades que acontecem as lógicas macrossistêmicas entre indivíduos e grupos, podendo ser, portanto, definidas como a "nova fábrica" da construção da sociedade ou, ainda melhor, a "nova questão social" para a tendência das diferentes culturas que vivem nos mesmos limites da cidade alimentando os processos de diferenciação em vez de integração e socialização.

Daí a urgência em utilizar pressupostos teóricos e metodológicos da Ciência da Informação para estudar os fenômenos dessa "nova questão social" e para investigar de que forma o uso estratégico da informação pode contribuir para a experimentação dos princípios do protagonismo social e a consequente diminuição da desigualdade. Nesta comunicação, apresenta-se um modelo de integração social produzido com base nos dados coletados a partir da experiência observada e vivenciada na Sanità, tendo como sujeitos a líder do trabalho social, os voluntários e os moradores italianos e estrangeiros. Todos eles são beneficiados pelas ações implantadas nessa realidade e que, aos poucos, também se tornam protagonistas de suas próprias vidas e dessas mesmas ações, a exemplo de jovens que eram estudantes de aulas de reforço escolar, das leituras mediadas, denominadas doposcuola, e, com o tempo, tornaram-se voluntários.

Vários aspectos analisados na Sanità são comuns às comunidades brasileiras, como os citados por Marcello e Licursi (2012). Para os autores, é perceptível uma

\footnotetext{
${ }_{3}$ A expressão quartieri sensibili foi utilizada por Magatti (2007) quando realizou uma pesquisa em periferias de dez cidades italianas, tendo como assistentes Cappelletti e Martinelli (2010). As autoras ressaltam que esse termo se refere aos bairros e áreas que se caracterizam - independentemente da localização geográfica no mapa da cidade a que pertencem - pela presença simultânea, embora variável, de uma multiplicidade de fatores de debilidade social: elevadas taxas de habitação popular; alta incidência de grupos vulneráveis e colocados à margem porum grau de sofrimento experimentado; concentração da população com baixo grau de instrução; carência de infraestrutura, estradas, transportes e instituições públicas; além da expansão da economia informal e ilegal.
} 
realidade não homogênea e altamente diferenciada internamente. Às vezes as condições de habitação variam inclusive ao longo da mesma rua. Existem diferentes grupos sociais que vivem em condições socioeconômicas diversas. Misturam-se situações de relativo bem- estar a situações de sofrimento. Essa realidade demonstra que as pesquisas realizadas nos quartieri sensibili são, segundo Magatti (2007), necessárias para a compreensão do futuro das cidades, da fragmentação e do deslocamento, da marginalização dos seus habitantes e das consequências desses fenômenos para toda a sociedade.

Esse conjunto de fenômenos de que trata Magatti puderam ser observados na pesquisa de campo durante as conversas com os moradores entrevistados em Sanità. Estes falam de uma piora da condição de vida no bairro agravada pela falta de ação governamental, o que leva os habitantes a lidarem sozinhos com todos os problemas. Para os jovens, a situação é ainda pior, já que estão mais suscetíveis a serem seduzidos por ofertas para atuarem na ilegalidade. Apesar desse quadro negativo, há na comunidade relações humanas de alto nível, bem como demonstrações de empreendedorismo social e de solidariedade que, aos poucos, provocam mudanças.

Isso demonstra que há pessoas e grupos capazes de suportar as pressões e perturbações para sonhar e agir para a mudança. Nesse cenário, a escola, a igreja e as associações solidárias são as únicas que atuam, apesar das dificuldades. Conforme Marcello e Licursi (2012), quem decidiu viver nesse espaço por vocação solidária experimenta um "isolamento ajudado", visto que é possível identificar nas escolhas políticas o fechamento de importantes monumentos e edifícios na Sanità, em uma tentativa deliberada de manter o bairro separado do resto da cidade e impenetrável até mesmo para os turistas e os próprios napolitanos.

Conforme a líder do trabalho social, identificada como $\mathbf{E}{ }^{4}$ na análise dos dados, a economia gira em torno do comércio local e de algumas pequenas fábricas de sapatos, bolsas e luvas de couro. Segundo E1, antigamente, Sanità era famosa por esse trabalho artesanal com o couro, mas atualmente há poucas fábricas familiares que ainda tentam resistir:"[...] aqui há uma economia de arranjar-se, ou seja, fazer pequenos trabalhos, os 'bicos', de ir levando como dá. Quem quer conseguir um trabalho fixo deve ir para outra cidade, para o norte do país", ressalta E1. Ela também explica que não se pode falar em melhora ou piora do quartiere por tratar-se de uma realidade muito complexa:

Quando cheguei ao bairro, há sete anos, vi muitos adolescentes na rua, que não tinham ocupação e não frequentavam a escola. Aqui há um alto índice de evasão escolar. Hoje penso que esse número está aos poucos diminuindo, a partir das ações realizadas para promover acesso ao ensino e ao conhecimento (E1)

De acordo com a líder, alguns moradores relatam que a situação está pior por causa da crise econômica que assola a Itália. Há ainda aqueles que não conseguem nem trabalhar informalmente e, por isso, tornam-se moradores de rua. Na Sanità há um abrigo com 150 vagas onde essas pessoas podem dormir e se alimentar, principalmente durante o inverno. $O$ abrigo foi criado por um padre que tem desenvolvido um trabalho empreendedor, segundo os moradores do bairro. Além disso, para mudar a realidade do quartiere e ajudar as famílias a saírem de um quadro de sofrimento, marginalização e baixa autoestima, um grupo de instituições solidárias coordenado pela líder do trabalho social desenvolve diversas ações diferenciadas em prol, principalmente, dos jovens, das crianças e também dos pais. Dentre essas ações encontram-se o acolhimento e o incentivo à consciência de automodificabilidade, ao exercício da cidadania e ao protagonismo social.

Esse é um trabalho que expande as fronteiras da integração social por meio de um modelo de intervenção cooperativa e dialógica com o envolvimento de voluntários provenientes da Sanità e de outros bairros. É preciso ressaltar que na comunidade estudada há uma alta incidência da população jovem - maior do que a média do restante da cidade -, pois as famílias são numerosas e, consequentemente, vulneráveis economicamente para suprir todas as necessidades dos filhos. O trabalho da líder e de todas as associações atuantes na Sanità deu início a um laboratório significativo de cidadania o qual reflete o poder de uma rede solidária e da construção de laços sociais, fortalecidos pela circulação da informação social

\footnotetext{
${ }^{4}$ Os sujeitos entrevistados durante a coleta de dados, não tiveram seus nomes mencionados, visando garantir o sigilo na pesquisa. Foram identificados por E1 até E23.
} 
entre os que desenvolvem as ações e os que delas usufruem. Isso propicia o surgimento da possibilidade de construção de novas relações, de uma consciência ativa do papel de cada um e do poder de todos. Leccardi (2000, p.160), ao refletir sobre a responsabilidade social, afirma que a "[... . subjetividade moral parece ser única, insubstituível, não universal e não universalizável, não reversível, exatamente como a responsabilidade a que dá forma" e, por isso mesmo, tem forte ligação com a existência do outro, com a subjetividade que nele se encontra.

As ações da líder do trabalho social e dos voluntários objetivam promover às crianças, aos adolescentes e aos adultos o acesso à educação, os quais, de outra forma, estariam fora do circuito escolar. As atividades de reforço escolar e de leitura mediada (doposcuola) foram criadas nos últimos anos e consistem no apoio e acompanhamento de crianças e adolescentes de escolas primárias e secundárias e de jovens que frequentam a escola superior - estes recebem uma ação adequada de tutoria personalizada. Além do espaço físico para estudar e da tutoria, essas ações sociais, segundo Marcello e Licursi (2012), dão a esses jovens confiança em suas capacidades, promovendo a consciência de que o "compromisso escolar" está ao alcance deles e que passa pela possibilidade de seu crescimento pessoal.

\section{Procedimentos metodológicos}

Por constituir um universo de pesquisa com características próprias, principalmente por ser em outro país, com outro idioma e ainda com a utilização de dialeto local, foi preciso, antes de ter o primeiro contato com Rione Sanità, aprender sobre o quartiere para entender sua dinâmica. Além de uma preparação "pessoal" da pesquisadora quanto a essa dinâmica e ao idioma, houve uma reflexão prévia sobre quais seriam os procedimentos metodológicos mais adequados, tendo a escolha recaído sobre os da abordagem qualitativa.

A razão para essa escolha se deu porque esse tipo de pesquisa não tenta aplicar conceitos preexistentes. Além disso, os instrumentos e técnicas de estudo são elaborados a partir do que o pesquisador sente ao conhecer os sujeitos e a realidade que os cerca. Infere-se que isso faz parte de uma postura socialmente respon- sável, com a qual a Ciência da Informação está cada vez mais em sintonia, uma área que procura entender as necessidades dos usuários/sujeitos e a relevância da informação em suas vidas. O método utilizado envolveu a participação e, de acordo com Brandão (1983, p.12), esse elemento determina "[...] um compromisso que subordina o próprio projeto científico de pesquisa ao projeto político dos grupos populares, cuja situação de classe, cultura ou história se quer conhecer porque se quer agir".

A pesquisa participante foi escolhida como método, tendo em vista que sua potencialidade está em seu deslocamento proposital das universidades para o campo concreto da realidade. "Este tipo de pesquisa modifica basicamente a estrutura acadêmica clássica na medida em que reduz as diferenças entre objeto e sujeito de estudo" (Fals Borda, 1983, p.60). A pesquisa participante procura, conforme Le Boterf (1984, p.52), auxiliar "[...] a população envolvida a identificar por si mesma os seus problemas, a realizar a análise crítica destes e a buscar as soluções adequadas". Dessa forma, a seleção dos problemas a serem estudados não surge apenas da decisão dos pesquisadores, mas sim da população envolvida.

O objetivo desse tipo de estudo é estar a serviço dos grupos ou categorias sociais mais desprovidas e exploradas a fim de desencadear e "[...] desenvolver a capacidade de análise e resolução dos problemas que enfrentam ou convivem cotidianamente" (Le Boterf, 1984, p.72). Desse modo, segundo Gianotten e Wit (1984, p.158), a pesquisa participante sempre está à procura de uma resposta coerente para permitir a socialização do conhecimento e a democratização dos processos de investigação e educação. Os autores ainda lembram que essa modalidade de estudo é:

[...] um conjunto de procedimentos operacionais e de técnicas que podem ser implementadas no interior de diferentes corpos teóricos e ideológicos; entretanto, suas características específicas fazem dela uma ferramenta necessária para todos aqueles programas que buscam a participação de setores populares na produção de novos conhecimentos (científicos) e em uma prática orientada a uma ação transformadora da sociedade (Gianotten \& Wit, 1984, p.159).

Essa visão da pesquisa participante, como sendo uma ferramenta potencial e orientada que visa produzir 
ações transformadoras na sociedade, deu segurança aos pesquisadores na adoção do método para o desenvolvimento do presente estudo, sobretudo por não haver um modelo único para isso. Porquanto, "[... . trata-se, na verdade, de adaptar em cada caso, o processo às condições particulares de cada situação concreta (os recursos, as limitações, o contexto sociopolítico, os objetivos perseguidos etc.)" (Le Boterf, 1984, p.52).

Nessa mesma linha de pensamento, Brandão (1984, p.252) esclarece que não existem "[...] modelos únicos e não há usos normativos de tipos de pesquisa participante, ela é um instrumento dentro da ação popular". Ainda conforme este autor, o mediador deve estar atento às decisões e às necessidades comunitárias, a fim de disponibilizar para a comunidade instrumentos do seu saber e de sua profissão.

Durante a pesquisa de campo foram utilizados os seguintes instrumentos: diário de campo, formulário de prospecção e roteiro de entrevista. Segundo Franco (2005), ao coletar os dados, registrá-los coletivamente, discuti-los e contextualizá-los constroem-se saberes visando o seu compartilhamento, em um processo único, dialético e transformador dos participantes e das condições existenciais: "Um processo que deve produzir transformações de sentido, ressignificações ao que fazemos ou pensamos" (p.499).

Para analisar os dados coletados utilizou-se a técnica de análise de conteúdo de Bardin (2009), com o estabelecimento de três categorias baseadas nos objetivos da pesquisa-sanduíche de entender a dinâmica da integração social na Sanità. A primeira, denominada integração social na Sanità, apresenta a forma como o trabalho cooperativo acontece, suas características e as teorias que o envolvem, a exemplo da concepção do paradigma social da Ciência da Informação a partir de Hjørland e Albrechtsen, da mediação, de Vygotsky, e da teoria de libertação, de Paulo Freire, que primam por uma ação dialógica.

A segunda categoria trata do regime de informação do trabalho social. Nela foram analisados os componentes do regime, quais sejam: ações, dispositivos, artefatos e sujeitos, mostrando a composição da rede Sanità e o seu modo de atuação, tendo como base as teorias de Foucault, Ekbia e González de Gómez. Já a terceira tem como foco revelar as competências em informação - dos voluntários, da líder do trabalho social e dos estudantes que participam de ações sociais necessárias para a realização do trabalho na Sanità. Para isso, foram utilizadas as teorias de Pieruccini, Dudziak, Varela, Feres e Belluzzo os quais trabalham com a concepção de competência em informação. Neste artigo, escolheu-se apresentar somente a primeira categoria por versar sobre a integração social na comunidade.

A primeira visita ao quartiere teve como objetivo conhecer as peculiaridades do local, a líder do trabalho social e o campo de pesquisa. Após essa visita, foi marcada uma estadia de alguns dias no local que, no entanto, não se concretizou em decorrência de alguns problemas internos de controle do território que tornariam a entrada no campo arriscada. Após esse período, a pesquisadora se estabeleceu por um pequeno período no quartiere para viver o campo de pesquisa no cotidiano, acompanhando as ações sociais e as visitas da líder aos moradores, conhecendo algumas realidades de famílias italianas e estrangeiras e observando as expressões de quem estava nas ruas. Em alguns momentos, um olhar de desconfiança de algumas pessoas quanto à presença dos pesquisadores pôde ser sentida, mas prosseguiu-se com o roteiro estabalecido no intuito de realizar as entrevistas e de participar das atividades do doposcuola e do curso de italiano.

Como critério de seleção de amostra, utilizou-se a intencionalidade, porque esta se reflete nos objetivos da pesquisa-sanduíche de analisar o processo de integração social em Sanità. A a ferramenta utilizada para isso foi a informação. De acordo com Gil (2006), a intencionalidade torna uma pesquisa qualitativamente mais rica, e os entrevistados são selecionados com base em certas características tidas como relevantes pelos pesquisadores e participantes. Escolheu-se como fontes de informação a líder do trabalho social, os voluntários habitantes ou não da Sanità, os pais dos alunos que participavam do doposcuola e os estudantes maiores de idade e os alunos do curso de italiano. Ressalta-se que alguns estudantes estrangeiros não concederam entrevista por não se sentirem seguros ao falar italiano.

A líder do trabalho social apresentou a pesquisadora a todos os entrevistados, tendo em vista evitar que a falta de confiança pudesse se tornar um obstáculo capaz de inviabilizar essa etapa. Durante esse primeiro contato, foram explicados os objetivos da pesquisa e o método de realização, além de ter sido solicitada a do 
termo de consentimento livre e esclarecido, em italiano, de acordo com a lei de privacidade do país. As entrevistas ocorreram antes ou depois das atividades do doposcuola ou do curso de italiano e, também, na casa de algumas pessoas as quais não puderam comparecer ao prédio do Instituto Ozanam, onde se realizaram as atividades, nos dias indicados.

O roteiro de entrevista foi dividido em três categorias conforme os grupos de entrevistados: líder do trabalho social, voluntários e pessoas atendidas pelas ações sociais. No geral, os tópicos versaram sobre a história do bairro, suas características, como ocorre o trabalho social, como se dá a comunicação entre a líder do mesmo, os voluntários e as pessoas atendidas pelas ações, bem como as dificuldades do bairro e do trabalho realizado, os progressos e os problemas. É importante destacar que, em uma área considerada de risco, o acompanhamento da líder e de uma voluntária originária da Sanità se tornou necessário para que a pesquisadora pudesse manter contato com os moradores.

Durante as entrevistas, fez-se uso de gravador digital formato MP4, além de câmara fotográfica com função de filmagem. A observação participante foi empregada, principalmente, para acompanhar o cotidiano dos moradores e tentar obter informações sobre a realidade em que se encontram. Para isso, utilizou-se o diário de campo.

\section{Resultados e Discussão}

Os dados coletados forneceram material suficiente para a construção do perfil de cada sujeito da pesquisa e de grupos de sujeitos, divididos em voluntários e usuários das ações sociais (exceto os menores de idade do doposcuola, caso em que optou-se por entrevistar os pais). A partir dessas informações, foi elaborado um quadro contendo: sexo, idade, profissão, papel desempenhado (atividades desenvolvidas) e local de proveniência (da Sanità ou de outros bairros de Nápoles).

Foram entrevistadas 23 pessoas, das quais 13 voluntários, bem como a líder do trabalho social e o pároco da comunidade, duas mães e um pai de alunos do doposcuola, dois estudantes estrangeiros do curso de italiano e três estudantes do doposcuola. Ressalta-se que foi necessário entrevistar um número maior de voluntários porque a finalidade era compreender como se realiza/funciona o trabalho de integração social. Além disso, percebeu-se que a maioria das pessoas atendidas por essas ações provinham de outros países, o que causou determinado impedimento para o estabelecimento de diálogo pela questão da língua e, por vezes, devido à timidez ou ao receio de alguma retaliação, algo que será explicado mais à frente.

Conforme o Quadro 1, a maioria dos voluntários era do sexo feminino e provinham da Sanità, um fato interessante, visto que os próprios moradores sentem o desejo de ver o progresso do lugar onde moram e, por isso, contribuem com as ações sociais. Entretanto, também é importante perceber que napolitanos de outros bairros se mobilizam para ajudar os quartieri sensibili. Para E1, é inspirador que jovens de outros bairros venham ajudar e façam um trabalho sério: "Eles cuidam bem das crianças e dos adolescentes. É belo ver que os jovens da Sanità se empenham como voluntários para ajudar o próprio bairro. Um dia desses, eu contava com uns 15 jovens voluntários no doposcuola".

Em relação aos estudantes do doposcuola e do curso de italiano, a maioria provém do Sri Lanka. Há uma grande comunidade de srilanqueses na Sanità e alguns dos alunos entrevistados provinham desse país. Mesmo tendo nascido em Nápoles, eles não têm cidadania italiana, porque, para obtê-la, é preciso ter 18 anos completos, como explica E15: "Eu e meus dois irmãos nascemos na Sanità, mas não temos a cidadania italiana, e sim srilanquesa. Devemos esperar até completar 18 anos de idade para dar entrada no processo de cidadania".

Quanto à profissão, entre os voluntários há professores, estudantes universitários, pedagogos, fisioterapeutas, aposentados e alguns desempregados. Os pais dos alunos e os estudantes do curso de italiano são, em sua maioria, diaristas, ou seja, trabalham em casas de famílias italianas na Sanità ou em outros bairros realizando serviços domésticos. De acordo com $\mathbf{E} 1$, os srilanqueses são muito solicitados para realizar esses serviços, por serem conhecidos pela sua eficiência nesse tipo de atividade e pelos cuidados com doentes e idosos, a exemplo de E19: "Eu trabalho todos os dias, de domingo a domingo, tenho três trabalhos, são três casas de famílias. Eu vim para cá para conseguir juntar algum dinheiro. No meu país se ganha muito mal".

Entre os voluntários há os que se dedicam ao doposcuola, a exemplo de $\mathbf{E 2}$, que começou a fazer 
Quadro 1. Caracterização dos entrevistados.

\begin{tabular}{|c|c|c|c|c|c|}
\hline Entrevistados & Sexo & Idade & Profissão & Papel desempenhado & Lugar de proveniência \\
\hline E1 & $\mathrm{F}$ & 71 & Freira & Líder do trabalho social & Rione Sanità \\
\hline E2 & M & 23 & Universitário & Voluntário/professor curso de italiano & Nápoles \\
\hline E3 & $\mathrm{F}$ & 51 & Não trabalha & Voluntária/professora curso de italiano & Nápoles \\
\hline E4 & $\mathrm{F}$ & 35 & Professora fundamental & Voluntária/professora curso de italiano & Rione Sanità \\
\hline E5 & M & 40 & Publicitário & Voluntário/professor curso de italiano & Nápoles \\
\hline E6 & $\mathrm{F}$ & 35 & Não trabalha & Voluntária/professora do doposcuola & Rione Sanità \\
\hline E7 & $\mathrm{F}$ & 22 & Assistente escolar & Voluntária/professora do doposcuola & Rione Sanità \\
\hline E8 & $\mathrm{F}$ & 48 & Professora particular & Voluntária/professora do doposcuola & Rione Sanità \\
\hline E9 & $\mathrm{F}$ & 24 & Universitária & Voluntária/professora do doposcuola & Nápoles \\
\hline E10 & $\mathrm{F}$ & 24 & Professora particular & Voluntária/professora do doposcuola & Rione Sanità \\
\hline E11 & $\mathrm{F}$ & 28 & Doutoranda & Voluntária/professora curso de italiano & Rione Sanità \\
\hline E12 & M & 24 & Fisioterapeuta & Voluntário/atividades recreativas & Nápoles \\
\hline E13 & $\mathrm{F}$ & 38 & Pedagoga & Voluntária/professora curso de italiano & Rione Sanità \\
\hline E14 & $\mathrm{F}$ & 62 & Aposentada & Voluntária/atividades diversas & Rione Sanità \\
\hline E15 & M & 18 & Estudante & Estudante do doposcuola & Sri Lanka \\
\hline E16 & $\mathrm{F}$ & 52 & Diarista & Mãe de uma estudante do doposcuola & Cabo Verde \\
\hline E17 & M & 53 & Padre & Pároco & Rione Sanità \\
\hline E18 & $\mathrm{F}$ & 49 & Diarista & Mãe de uma estudante do doposcuola & Cabo Verde \\
\hline E19 & M & 22 & Diarista & Estudante de italiano & Sri Lanka \\
\hline E20 & $\mathrm{F}$ & 37 & Diarista & Estudante de italiano & Rússia \\
\hline E21 & M & 45 & Vive de bicos & Pai de aluna do doposcuola & Rione Sanità \\
\hline E22 & $\mathrm{F}$ & 18 & Estudante & Estudante do doposcuola & Sri Lanka \\
\hline E23 & $F$ & 19 & Estudante & Estudante do doposcuola & Sri Lanka \\
\hline
\end{tabular}

Fonte: Elaborado pela autora (2014).

Nota: F: Feminino; M: Masculino

voluntariado há cinco anos a convite de uma amiga que é voluntária na Sanità: "Eu venho uma vez por semana para ajudar no doposcuola e trabalho com todas as séries, depende da necessidade das crianças. A líder do trabalho social équem organiza para onde devo ire o que devo fazer". No caso de E3, a ajuda está relacionada à literatura e ao italiano: "Eu ajudo as crianças com dúvidas relacionadas às matérias que tenho mais afinidade, incentivando a leitura, o aprendizado".

Há ainda os voluntários que desempenham a função de professores de italiano como E4 e E5. Ambos trabalham juntos em uma sala do curso de língua noturno para estrangeiros e explicam de que forma lecionam: "Desenvolvemos em sala de aula atividades lúdicas para o ensino da língua e da cultura italiana. Os alunos também mostram um pouco da cultura deles e assim o aprendizado é mútuo". Em consonância com a opinião dos dois professores, E11 também ensina italiano e conta: "Esse trabalho é divertido, sinto-me beneficiada, algumas vezes não consigo explicar uma palavra, faço desenhos, os alunos se divertem e eu também".
O doposcuola ocorre de segunda a sexta-feira, tendo início às $15 \mathrm{~h} 30$ e prosseguindo normalmente até as $18 \mathrm{~h}$, dependendo das necessidades dos alunos. A organização é realizada pela líder do trabalho social, que divide os alunos de acordo com o nível de instrução, ou seja, o ano em que eles se encontram na escola. Os voluntários são divididos em duplas ou em grupos de três ou quatro integrantes para cada sala. Além do doposcuola e do curso de italiano, um voluntário E12 desenvolve atividades recreativas e esportivas com os adolescentes da Sanità aos sábados: "Fazemos um percurso lúdico junto com o percurso educativo para alguns adolescentes italianos que vivem na Sanità visando crescermos juntos". Segundo ele, a ideia é incentivar a legalidade, ou seja, conscientizar os jovens da importância de estudar e não se envolver com o "trabalho" ilegal disseminado no quartiere.

O trabalho social ainda conta com uma voluntária, E10, proveniente da Sanità, a qual demonstra ser uma das mais atuantes: 
Há sete anos comecei o voluntariado aqui. A líder do trabalho social me viu na rua e perguntou se eu não queria vir ajudar. Eu disse sim e comecei. Eu ajudo em praticamente tudo no doposcuola na parte administrativa e como guia para mostrar o bairro aos visitantes e pesquisadores como você.

O perfil dos entrevistados levou à reflexão de que esse é um trabalho realizado em rede, e de que, apesar das dificuldades diárias, como problemas de desigualdade, de pobreza e de violência, há sempre acolhimento. Isso torna o quartiere um lugar de esperança que tem como base a educação e o uso da informação para fortalecimento da rede Sanità, formada por voluntários e pelas pessoas que recebem as ações. Estas demonstram assumir, progressivamente, o papel de protagonistas de suas próprias vidas, desejosos de progredir e de melhorar a realidade que os cercam.

As ações empreendidas na Sanità visam à integração social e à libertação e têm como base a educação, a disseminação do saber, a recusa à acomodação e o estímulo à mobilização e à superação das adversidades, ou seja, primam por ações mediadas pelo diálogo. Freire (1985) esclarece essa questão ao explicar que a condição básica para a conscientização é que seu agente seja um sujeito, um ser consciente.

Essa conscientização ocorre por um processo específico e exclusivamente humano, como a educação, que, permeada por práticas sociais, leva a refletir, a partir da visão de Hjørland e Albrechtsen (1995), sobre o paradigma da apropriação da informação social na Ciência da Informação. Este preconiza que os sujeitos são protagonistas de suas próprias histórias e procuram se apropriar para produzir conhecimento para benefício próprio e do grupo, o que fica explícito na fala de $\mathbf{E} \mathbf{1}$, a qual faz trabalhos sociais há mais de 30 anos. Para ela, crianças e jovens têm o direito de estudar, mas nem sempre a escola favorece o acolhimento de crianças e jovens de rua e, por isso, " $[. .$.$] devemos intervir e ajudar$ através da força do voluntariado, por exemplo. Essa força do voluntariado eu encontro aqui, onde as pessoas se dedicam a esse empenho continuamente, ajudando os que precisam através da educação".

Um dos voluntários, E2 reforça a fala de E1 ao dizer que se sente muito bem fazendo esse tipo de trabalho, pois, ao transmitir cultura, recebe-se "[...] em troca diversos sentimentos muito humanos e aprendemos sobre uma realidade em que pensamos estar muito distante da nossa, principalmente em Nápoles, uma cidade de contrastes, que tem muita riqueza, mas também muita pobreza", enfatizou E2.

As ações da líder do trabalho social e dos voluntários ajudam a transformar a comunidade e, segundo Freire (1989), podem captar a realidade e expressá-la por meio de sua linguagem criadora, incentivando homens e mulheres a participarem do seu contexto como protagonistas, favorecendo, assim, a integração social que foi percebida no campo de pesquisa durante a observação participante. Foi possível visualizar no doposcuola, por exemplo, crianças italianas e estrangeiras se ajudando nas atividades escolares, sem discriminação, em plena sintonia no modo de ser criança. Isso pôde ser comprovado nas palavras de E16, mãe de uma das crianças estrangeiras do doposcuola: "Aqui todas as crianças estão integradas. Eu tenho consciência da necessidade de trazer minha filha para estudar e ela está muito feliz. Posso trabalhar tranquila. Esse trabalho desenvolvido é muito importante para nós".

Segundo $\mathbf{E} 1$, os pais se sentem seguros em deixar seus filhos visto que se estabelece uma relação de amizade com as famílias das crianças do doposcuola: "[...] para miméimportantever como eles moram paraentender a situação de cada um e ver como ajudá-los. Nós procuramos compreender e não julgar. Nossa rede de amigos auxilia as famílias de diversas formas, com os doentes, por exemplo".

A fala de $\mathbf{E} 1$ demonstra que exerce um papel fundamental como mediadora, como a pessoa que entende a necessidade da interação para o bom desempenho do trabalho, e isso ocorre porque, segundo Vygotsky (1984), é pela interação social, ao adquirir a condição humana na relação com o mundo mediado por instrumentos culturais - signo, palavra, símbolo - que o ser humano se desenvolve. Para E10, o trabalho desenvolvido na Sanità atua também na questão moral e relacional, uma vez que "[...] há quem venha aqui para ter uma palavra, um conforto. Aqueles que têm problemas na familia vêm para conversar com a líder do trabalho social. [...] Eu vejo muito progresso com esse trabalho, nas crianças e nos jovens. E os pais também estão muito satisfeitos". 
A integração social ocorre na Sanità, conforme E20, por se tratar de um bairro pobre. Segundo ela, em outras partes da cidade de Nápoles consideradas mais ricas há certo desprezo e preconceito por quem é estrangeiro:

Aqui na Sanità as pessoas são muito abertas, te tratam muito bem, te ajudam. Já nas zonas que vivem os ricos eles te tratam mal, te respondem mal, não explicam as coisas. Falam palavras difíceis para mostrarem que são intelectuais, que são melhores do que os outros [...] Eu moro há cinco anos na Sanità. [...] Criamos um clima de amizade com estrangeiros ecom italianos, aténa rua mesmo. Aos poucos nos tornamos napolitanos. Quando volto ao meu país, sinto-me estranha lá, já me habituei na Itália.

Essa realidade é confirmada por E13, ao afirmar que a Sanità é vista de forma errônea pelo restante da cidade: "A integração social é difícil, porque a Itália é muito classista, não racista, sempre se observa onde a pessoa vive, em qual bairro. Se admira quem tem dinheiro, poder. [... . A Sanità é julgada mal, mas aqui é belo. As pessoas são acolhedoras". Entretanto E10 diz que na verdade "[...] alguns estrangeiros não querem se integrar, vivem fechados em comunidades, como os srilanqueses. Já as crianças estrangeiras que fazem o doposcuola são integradas com as crianças italianas. Algumas até afirmam serem napolitanas".

E17 esclarece essa questão dizendo que somente a partir da segunda geração de estrangeiros da Sanità é que poderá haver uma maior integração social em virtude da primeira não falar bem o italiano. A segunda geração já nasceu na Itália e está mais interessada na cultura. Além disso, os srilanqueses casam, em sua maioria, entre si, e normalmente os pais escolhem as esposas, logo, continuam a viver em comunidades fechadas e não se integram.

É através da língua que um verdadeiro diálogo ocorre ese pode começar o processo de integração. Porisso, durante as aulas, os professores de italiano sempre explicam as palavras usando representações culturais, pois não há como traduzir determinados termos que não há na língua deles. E com essa experiência aprendemos também com a cultura do outro, pois na concepção de muitas pessoas, os estrangeiros devem se adequar a nossa cultura, mas isso não é integração quando impo- mos nosso jeito de viver, devemos estar abertos para entender erespeitar o modo de viver deles. [...] O que posso afirmar é que as atividades do doposcuola e o curso de italiano ajudam na integração social, tendo em vista que aqui há uma grande evasão escolar, pois alguns pais colocam os filhos para trabalhar desde pequenos nos bares, nos negócios e comércios familiares. Isso ocorre tanto com as famílias italianas quanto estrangeiras (E17).

Ainda a respeito dessa questão, E9 contou que já ouviu crianças italianas reclamarem que as estrangeiras recebem mais atenção, "[...] o que não é verdade, damos mais atenção a quem tem mais necessidade. Mas no final são crianças e tudo fica bem. O pior é quando as mães falam esse tipo de coisa, como já ocorreu, e isso influencia as crianças, que escutam o preconceito em casa e o reproduzem".

Esses depoimentos demonstram o quão complexo é o processo de integração social em uma realidade repleta de particularidades, com pessoas provenientes de diversas culturas. Isso leva a refletir que essa integração ocorre por meio de um processo que perpassa diversas áreas com uma atuação em rede, ou seja, na Sanità as ações ocorrem com os moradores e não apenas para eles. Esse é um processo lento, mas constante de conscientização, que visa eliminar preconceitos sociais e raciais, colocando em prática o que ressalta Freire (1987, p.29) "Ninguém liberta ninguém, ninguém se liberta sozinho, os homens se libertam em comunhão".

Além da rede Sanità, há uma rede maior que abrange associações de toda a Itália com o objetivo, segundo E1, de trocar experiências sobre as ações sociais. "Sozinho não se faz esse trabalho, porque há tempos difíceis. Uma vez por ano, todas as associações se reúnem e fazemos uma formação para as crianças e os jovens. Os amigos de outras associações também vêm nos visitar na Sanità e ajudar com alguma ação". A realidade retratada não está tão distante do que ocorre nas comunidades brasileiras que, apesar de serem formadas essencialmente por nativos, sofrem de diversos problemas de preconceito pelo restante da cidade, pois, como na Itália, também abriga uma cultura classista.

A partir dessa experiência no campo de pesquisa italiano, elaborou-se um possível modelo de integração social, tendo como inspiração os seguintes modelos: 
comunicação todos-todos, de Mendonça (2007); mediação com visão inclusiva, de Belmonte (2007); e modelo de desenvolvimento humano, de Sirvent (1984). O formato gráfico desse modelo foi inspirado em uma figura de Grossi e Bordin (1993), os quais trabalham na perspectiva do construtivismo pós-piagetiano. O objetivo da elaboração do modelo para Sanità é mostrar como ocorre o processo de integração social naquele contexto, tendo como sujeitos a líder do trabalho social, os voluntários e os moradores italianos e estrangeiros, que são beneficiados pelas ações implantadas naquela realidade e que também se tornam, aos poucos, protagonistas de suas próprias vidas e dessas mesmas ações, a exemplo de jovens que eram estudantes do doposcuola e, com o tempo, se tornaram voluntários.

Na Figura 1, é apresentado o modelo de integração social da Sanità para, em seguida, detalhar suas variáveis (contexto social/protagonismo social, cultura/ aculturação, doposcuola/competências, outro, mediação, informação, conhecimento, comunicação e inteligência) e sua forma de convergência com aqueles que serviram

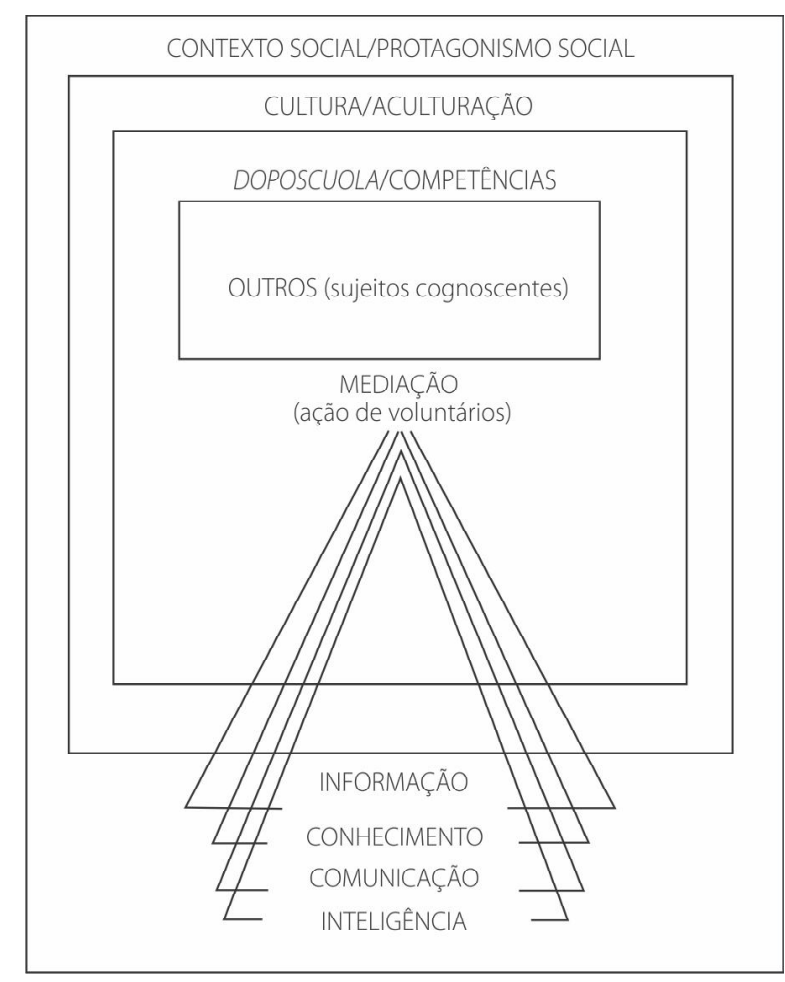

Figura 1. Modelo de integração social da Sanitá. Fonte: Adaptado de Grossi e Bordin (1993). de inspiração. É possível observar como se constituem as relações entre os seus componentes para se chegar ao objetivo final, que é o protagonismo social dos que compõem aquela realidade/contexto social. Ser protagonista é poder atuar de forma central nos contextos históricos e coletivos, com consciência da relevância de suas ações, da realidade que o cerca e da importância de se empoderar das informações necessárias para modificar sua vida.

Os elementos cultura/aculturação estão relacionados à possível imposição da cultura aos estrangeiros, o que, de acordo com relatos dos professores/voluntários entrevistados, não existe na Sanità, visto que procuram compreender a cultura do outro e respeitá-la. Entretanto, ao longo da estadia dos pesquisadores, foi possível perceber ações discriminatórias. Vizinhos de uma associação voluntária, que atende os alunos estrangeiros do doposcuola, reclamaram constantemente do modo de ser e de agir desses alunos.

O componente doposcuola/competências foi escolhido para constar no modelo de integração social por se configurar como uma ferramenta mediadora do protagonismo ao proporcionar o desenvolvimento de competências a partir do incentivo à leitura e à aprendizagem, com base na ação dialógica freireana e no construtivismo piagetiano.

O doposcuola, assim como o curso de italiano, objetiva desenvolver competências nos participantes de modo que possam intervir em suas realidades e em seu contexto social, colocando em prática a ênfase dada por Perrenoud (1999) à noção de competência direcionada à capacidade de agir eficazmente em um determinado tipo de situação, colocando em ação e em sinergia vários recursos cognitivos complementares. Entre eles estão os conhecimentos e representações da realidade construídas e armazenadas a partir da experiência e da formação de cada um.

O outro, nesse modelo, são os sujeitos cognoscentes/moradores da Sanità, para os quais as ações educacionais são pensadas e realizadas pelos voluntários e pela líder do trabalho social. Já a mediação (ação de voluntários) atua com intencionalidade e com reciprocidade, procurando respeitar as diferenças culturais e se constituindo como elemento essencial no processo 
de intervenção humana para assistir a busca de informação e a aprendizagem a partir do acesso e uso da informação, como explica Kuhlthau (1993). Essa intervenção acontece pela interação social, a qual proporciona o desenvolvimento do ser humano, o que ocorre, conforme Vygotsky (1991), quando o desenvolvimento cognitivo mantém estreita relação com a aprendizagem, quando há apropriação do conhecimento produzido pela humanidade e estabelecimento de relações com o meio. Além disso, nesse contexto, é primordial haver um intermediário, um organizador de processos formativos, ou seja, é necessária a atuação do mediador, o qual, de acordo com Belmonte (2007), seria aquele que contribui para a autêntica construção da obra mais complexa que se pode empreender: a formação de uma pessoa.

Para isso, o mediador se utiliza da informação para construir conhecimento. Emprega os processos comunicativos visando ativar a inteligência dos futuros protagonistas. Todos esses elementos do modelo de integração social da Sanità convergem para que todos convivam com as diferenças e não em guetos. É isso o que prega o protagonismo social, o qual se impõe contra a indiferença e o isolamento social, primando pelo incentivo do agir coletivo, da convicção de poder mudar as coisas.

Em relação às fontes de inspiração para criação do modelo de integração social, foi utilizado o modelo de comunicação todos-todos de Mendonça (2007), isso porque entende-se que a comunicação é um dos pilares do processo de integração social. Nele, a líder do trabalho social se utiliza dos processos comunicativos para ter o primeiro contato tanto com os futuros voluntários quanto com moradores, italianos e estrangeiros. Nesse último caso, a mensagem transmitida pela líder pode estar repleta de interferências causadas pelas barreiras linguísticas e culturais.

Para diminuir essas barreiras/interferências, a experiência de anos desse trabalho social na Sanità promove, como explica Mendonça (2007), um conhecimento construído ao longo da história de vida dos atores do processo, mediado e redesenhado para nova aplicabilidade na comunidade, à qual pertencem os receptores e produtores e onde ocorrem as trocas de saberes de forma colaborativa e livre. Nessa perspectiva, os canais de comunicação devem ser vistos como o" [...] espaço interno de convergência dos conteúdos produzidos, informações circuladas, conhecimento acumulado ou mesmo contextualizado" Mendonça (2007, p.34).

Ainda segundo Mendonça (2007, p.34), a mensagem deve ser compreendida como "[...] informação mediada ou distribuída no conjunto do processo por qualquer elemento em qualquer formato". Já as interferências podem servir como elemento motivador para a construção de estratégias para as futuras comunicações, no sentido de empregar o conhecimento adquirido e acumulado dos contatos anteriores e das barreiras sentidas. Em outras palavras, essas interferências são, para a líder do trabalho social, elementos importantes para formar estoques de informação e de conhecimento disponíveis para as futuras aproximações com os moradores naquele contexto social.

Todo esse processo de integração social é permeado pela mediação. Sem ela não é possível superar as diversas barreiras que um trabalho dessa natureza, em um contexto social dessa complexidade, impõe. Como explica Belmonte (2007), a mediação é uma qualidade essencial à interação, uma fonte de transmissão cultural significativa e afetiva, bem como uma orientação ao pensamento casual, estabelecendo relações, avançando os efeitos de um ato.

Para transpor as barreiras culturais, sociais e linguísticas a líder do trabalho social/mediadora deve, conforme Belmonte (2007), internalizar a mediação como potencializadora do desenvolvimento integral, como um fator humanizador de transmissão cultural. Deve ainda procurar acompanhar e se aproximar dos mediados, formando laços de simpatia ou de amizade em uma tentativa de aprofundar as relações. Estimular a autoestima dos moradores, ajudando-os a compreender o contexto em que vivem e procurando dotá-los de habilidades cognitivas e de competências, visando o desenvolvimento do protagonismo social nesses sujeitos, ou seja, incentivando-os a se tornarem, segundo Perrotti e Pieruccini (2007), sujeitos e objetos dos processos em que estão inseridos, produtores e criadores de significados, de sentidos e de práticas sociais. Esse ato de participar dos processos é um aspecto da motivação, como esclarece Sirvent (1984), que impulsiona a ação e, 
por isso, deve ocorrer em um movimento progressivo de construção para o bem de todos.

Para se tornar protagonista na Sanità é preciso superar as barreiras já citadas e as constantes mensagens discriminatórias provenientes de outras partes da cidade. Esse fator tem um agravante para os moradores estrangeiros que sofrem duplamente com a marginalização e o xenofobismo. Por isso, o trabalho de integração social visa incentivar, nos moradores, um protagonismo baseado no desenvolvimento das habilidades cognitivas, no empoderamento de informações necessárias, no encorajamento de autovalorização, de autoestima e de autonomia, tendo a educação como base para isso.

Como percebido nas entrevistas realizadas na realidade napolitana, os professores voluntários dos cursos de língua procuram compreender e valorizar a cultura do outro, não tentando impor a cultura italiana. Pelo contrário, há uma tentativa constante de mediar as relações entre italianos e estrangeiros atendidos pela líder do trabalho social, mostrando que, para sair do estado de marginalização, todos devem participar ativamente do espaço público, do processo de emancipação social e das cobranças perante o poder público para a construção de uma vida digna.

Nesse contexto, faz-se necessário que os protagonistas sejam dotados de competências em informação, conceituadas por Bruce (1997) como a habilidade em acessar, avaliar, organizar e usar a informação a fim de aprender, resolver problemas, tomar decisões em contextos formais e informais de aprendizagem, no trabalho, em casa e em ambientes educacionais, ligadas ao pensamento crítico e reflexivo. Para desenvolvê-las, é preciso haver um movimento constante de aprendizagem, levando em consideração as necessidades cognitivas e sociais dos sujeitos, respeitando sua forma de agir e incentivando-os a prosseguir e a desejar as transformações benéficas. Um exemplo disso são os estudantes que se preparam, apesar de todas as dificuldades, para a entrada na universidade, os quais usam seu tempo também para se dedicar à música e às atividades que beneficiam suas famílias. Pode-se inferir que as competências, nesses indivíduos, são construídas na prática, com características como a persistência, a determinação e a vontade de desenvolver determinadas habilidades cognitivas para alcançar os objetivos traçados.
Cabe ainda ressaltar que esse modelo de integração social conta com conhecimentos adquiridos durante a pesquisa do doutorado-sanduíche, dando suporte a partir de elementos constituídos por teorias e metodologias, os quais serviram como subsídios indicadores para planejar as ações de informação implantadas no campo de pesquisa brasileiro. Da mesma maneira, fomentaram a produção e implementação de um modelo de mediação da informação, o qual possibilitou a potencialização do protagonismo social nos moradores dessa comunidade ao passarem por alguns estágios de empoderamento da informação, ao se apropriarem dela e a utilizarem para desenvolver um conjunto de conhecimentos, aptidões e habilidades.

\section{Conclusão}

Resolver os problemas de fragmentação e marginalização social de quem vive nesses contextos urbanos específicos não é simples. É necessário considerar que os fenômenos são muito prevalentes e difíceis de penetrar, pois há quem se beneficie dessa situação social para obter vantagens. Por essas razões, sabe-se que os processos de reabilitação e reinserção social dessas realidades requerem tempo, conhecimento específico e ações em médio e longo prazo, perseverança e a não intenção de modelar realidades.

É preciso ainda promover palestras ou encontros com os moradores para conscientizá-los da situação em que se encontram, dialogando sobre a necessidade da aquisição de determinadas competências para saírem do estado de marginalização. Assim, todo o trabalho/ação realizado dentro de um quartiere deve ter a real participação de seus membros, mesmo que não seja da maioria. Além disso, quem deseja atuar em uma comunidade, brasileira ou italiana, deve ter em mente que as ações de informação e as conexões necessárias entre o mediador e os mediados, pesquisador e protagonistas, só podem efetivamente ocorrer por meio do diálogo, da mediação e das construções socialmente elaboradas do conhecimento, ou seja, é preciso pensar na alteridade, vendo-se no outro e com ele se preocupando.

É da condição de incerteza que o sujeito experimenta, no campo da ética, o impulso de agir de forma responsável, de encontrar as bases das próprias ações. 
Um possível caminho para tentar mudar essa realidade seria possibilitar o empoderamento dos moradores dos quartieri sensibili e das comunidades brasileiras promovendo várias medidas de educação básica para crianças e jovens, de incentivo à leitura mediada, de acesso à informação e ao conhecimento, além de centros de aconselhamento para as famílias.

A vivência na Sanitá fez com que fosse possível compreender que, para atuar contra a marginalização, a fragmentação e os seus efeitos, uma forte e nova dinâmica social, proveniente da mobilização de indivíduos e de grupos, deve ser constituída para aqueles que anseiam por retecer suas vidas e a realidade circundante, colocando em prática ações concretas refletidas de forma cooperada e com metas consolidadas. Destaca-se, também, que a identidade de grupos e os laços sociais precisam ser repensados, compreendendo que apenas ao se respeitar o diferente pode-se compreender o sujeito como único, mas que necessita da união com o outro para sair do estado de degradação. A única dimensão possível é aquela da experimentação contínua. Essa opção, no entanto, requer uma leitura permanente das

\section{Referências}

Bardin, L. Análise de conteúdo. Lisboa: Edições 70, 2009.

Belmonte, L.T. El professor mediador del aprendizaje. Chile: Arrayán Editores, 2007.

Brandão, C.R. Pesquisar-participar. In: Brandão, C.R. (Org.). Pesquisa participante. 3.ed. São Paulo: Brasiliense, 1983. p.9-17.

Brandão, C.R. A participação da pesquisa no trabalho popular. In: Brandão, C.R. (Org.). Repensando a pesquisa participante. São Paulo: Brasiliense, 1984. p.223-252.

Bruce, C. The seven faces of information literacy. Adelaide: Auslib Press, 1997.

Cappelletti, P.; Martinelli, M. Animare la città: Percorsi di community building. Trento: Erickson, 2010.

Cappelletti, P.; Martinelli, M. Periferie umane nelle città frantumate. Convegno Nazionale Caritas Diocesane. Torino: Centro Congressi Lingotto, 2009.

Fals Borda, O. Aspectos teóricos da pesquisa participante: considerações sobre o significado e o papel da ciência na participação popular. In: Brandão, C.R. (Org.). Pesquisa participante. 3.ed. São Paulo: Brasiliense, 1983. p.42-62.

Franco, M.A.S. Pedagogia da pesquisa-ação. Educação e Pesquisa, v.31, n.3, p.483-502, 2005.

Freire, P. A importância do ato de ler. 11.ed. São Paulo: Cortez, 1985. condições do contexto, um acompanhamento constante de processos e uma presença assídua nos pontos de fragilidade, empreendendo ações voltadas para a escolarização e para a formação.

Nessa perspectiva, esforços devem ser empreendidos para identificar barreiras na mediação e vencê-las pelos canais de comunicação, das fontes, das possibilidades e da comunicação oral, identificando que linguagem usar nesse contexto social da comunidade e quais os meios comunicacionais utilizados para eliminar as barreiras. Além disso, a introdução dos princípios do protagonismo social fortalece as ações de informação e devem estar atrelados à oportunidade de possibilitar formas concretas, reais e legítimas de apropriação da informação, de autonomia e de empoderamento cultural e social.

\section{Agradecimentos}

À Coordenação de Aperfeiçoamento de Pessoal de Nível Superior pelo financiamento do Processo de n 7534-13-2.
Freire, P. Pedagogia do oprimido. 27.ed. Rio de Janeiro: Paz e Terra, 1987.

Freire, P. Educação e mudança. 12.ed. Rio de Janeiro: Paz e Terra, 1989.

Gianotten, V.; Wit, T. Pesquisa participante em um contexto de economia camponesa. In: Brandão, C.R. (Org.). Repensando a pesquisa participante. São Paulo: Brasiliense, 1984. p.158-188.

Gil, A.C. Como elaborar projetos de pesquisa. 4.ed. São Paulo: Atlas, 2006.

Grossi, E.P.; Bordin, J. Paixão de aprender. Petrópolis: Vozes, 1993.

Hjørland, B.; Albrechtsen, H. Toward a new horizon in information science: Domain-analysis. Journal of the American Society of Information Science, v.46, n.6, p.400-425, 1995.

Kuhlthau, C.C. Seeking meaning: A process approach to library and information services. Norwood: Ablex, 1993.

Le Boterf, G. Pesquisa participante: propostas e reflexões metodológicas. In: Brandão, C.R. (Org.). Repensando a pesquisa participante. São Paulo: Brasiliense, 1984. p.51-81.

Leccardi, C. Responsabilità. In: Melucci, A. (Org.). Parole chiave. Roma: Carocci, 2000. p.157-168.

Magatti, M. La città abbandonata: dove sono e come cambiano le periferie italiane. Bologna: II Mulino, 2007. 
Marcello, G.; Licursi, S. Un'esperienza laboratoriale nel Quartiere della Sanità a Napoli. Alcune riflessioni da una ricerca in corso. In: Espanet Conference, 2012, Roma. Annali... Roma: Espanet Italia, 2012. Disponibile: <http://www.espanet-italia.net/ programma-della-conferenza/23-conferenza2012/ programma-conferenza2012/117-sessione-q1.html>. Accesso: 20 maggi, 2014.

Mendonça, A.V.M. Os processos de comunicação e o modelo todos-todos: uma relação possível com o programa saúde da família. Brasília: UnB, 2007. (Série Tempus).

Perrenoud, P. Construir as competências desde a escola. Porto Alegre: Artmed, 1999.
Perrotti, E.; Pieruccini, I. Infoeducação: saberes e fazeres da contemporaneidade. In: Lara, M.L. G.; Fujino, A.; Noronha, D.P. (Org.). Informação e contemporaneidade: perspectivas. Recife: Néctar, 2007. p.47-96.

Sirvent, M.T. (Org.) Educação comunitária: a experiência do Espírito Santo. São Paulo: Brasiliense, 1984.

Vygotsky, L.S. A formação social da mente: o desenvolvimento dos processos psicológicos superiores. 4.ed. São Paulo: Martins Fontes, 1991.

Vygotsky, L.S. A construção do pensamento e linguagem. São Paulo: Martins Fontes, 1984. 